\title{
ARTÍCULOS
}

\section{Génesis de la episteme de lo criminal: anotaciones en torno a Beccaria, Ferri y Foucault*}

\section{The genesis of the episteme of crime: notes around Beccaria, Ferri and Foucault}

\author{
DAVID J. Domínguez \\ Universidad Complutense de Madrid \\ dadomi01@ucm.es \\ ORCID iD: https://orcid.org/0000-0002-4902-9555 \\ Mario Domínguez SÁnchez-Pinilla \\ Universidad Complutense de Madrid \\ mariodos@cps.ucm.es \\ ORCID iD: https://orcid.org/0000-0002-6211-3081
}

\begin{abstract}
Resumen: Los principios fundamentales de la escuela clásica utilitarista (el libre albedrío, la proporción entre los delitos y las penas, y la uniformidad de las penas) caracterizan dicha tendencia como una criminología administrativa y legal. Ello tuvo dos implicaciones. Por una parte, se obviaron los motivos y las causas últimas del comportamiento y las consecuencias desiguales de una norma arbitraria. Por otra, se redujo la función del juez a la aplicación de la ley, mientras que a esta le correspondía fijar una pena para cada delito. A finales del siglo xIx tales principios conocen la irrupción progresiva de otra episteme punitiva surgida como consecuencia de la colonización del espacio jurídico por parte de las ciencias positivas (médicas y sociales) y los programas de acción etiológicos. No se trata de un programa planificado y preestablecido, sino de la confluencia de una serie de teorías y de programas de prevención penales que Michel Foucault resumió como la constatación de que la ley funciona cada vez más como una norma. De ese modo, la criminalidad además de constituir el objeto de un interés científico constituye también el indicador de una problemática social y por tanto su inserción en una economía de poder cambiante.
\end{abstract}

Palabras clave: Racionalidad punitiva; penalismo utilitarista; correccionalismo; Foucault.

Cómo citar este artículo / Citation: Domínguez, David J. y Domínguez Sánchez-Pinilla, Mario (2021) "Génesis de la episteme de lo criminal: anotaciones en torno a Beccaria, Ferri y Foucault". Isegoría, 65: e13. https://doi. org/10.3989/isegoria.2021.65.13

ABSTRACT: The fundamental principles of the classical utilitarian school (free will, the proportion between offences and penalties, the uniformity of penalties) characterize this trend as an administrative and legal criminology. This had two implications. On the one hand, the motives, and ultimate causes of the behavior and the unequal consequences of an arbitrary rule were ignored. On the other hand, the role of the judge was reduced to enforcing the law, while it was up to the judge to set a penalty for each offence. At the end of the nineteenth century, these principles saw the gradual emergence of another punitive episteme that had emerged as a result of the colonization of the legal space by the positive sciences (medical and social) and etiological action programs. This was not a planned and pre-established course, but the confluence of a series of theories and programs for penal prevention that Michel Foucault summarized as the realization that the law was increasingly functioning as a norm. Now, criminality, besides being the object of scientific interest, also constitutes the indicator of a social problem and therefore its insertion in an economy of changing power.

Keywords: Punitive rationality; Utilitarian penalism; Correctionalism; Foucault.

Recibido: 6 agosto 2020. Aceptado: 18 octubre 2021.

Copyright: (C) 2021 CSIC. Este es un artículo de acceso abierto distribuido bajo los términos de la licencia de uso y distribución Creative Commons Reconocimiento 4.0 Internacional (CC BY 4.0). 


\section{INTRODUCCIÓN}

La intervención de la ley supone, en la historia del poder de castigar, una transformación cualitativa importante, pues corresponde a la idea de legitimación del poder y abarca un fenómeno más general que supone la legitimidad a través de la legalidad. Cabe subrayar que el concepto de criminalidad constituye una invención vinculada a la existencia de instancias centrales de poder, por ello, lo primero que cabe constar es que los productos de toda acción punitiva y sus transformaciones históricas no constituyen el producto de un mero capricho oportunista o de un golpe de genio humanista, sino que se insertan en una transformación profunda de las políticas penalistas y de las funciones sociales del castigo. Considerando lo anterior, nuestro propósito parte de una premisa: cuestionar la representación de la historia punitiva como una secuencia de reformas humanitarias hacia la civilidad y cuya plasmación pudiera atribuirse a la potencia de las ideas de los reformadores. Por el contrario, consideramos que las dinámicas sociales donde se insertan las racionalidades punitivas, en especial las que afectan a los estratos dominados, constituyen la principal variable causal; de ahí la analogía entre los mecanismos de regulación social y las transformaciones del control del delito. En efecto, en el paso de las estrategias penales basadas en la ley y que tienen como referente al homo penalis, a la normalización científico-judicial con criterios correccionalistas de las clases peligrosas y la identificación de la criminalidad, nos encontraremos con un límite estructural a cualquier esfuerzo de reforma o "proceso civilizatorio": la situación global de la clase trabajadora, la que puebla mayoritariamente los sistemas punitivos, y cuyo dominio no se restringe únicamente al ámbito laboral sino que implica transformaciones en las estrategias de dominación.

Comenzaremos por el análisis de los presupuestos de la "penalidad de la ley" y de la "penalidad de la norma". Dos conceptos que, a pesar de su aparente cercanía, presentan diferencias sustanciales en cuanto a sus premisas y sus protocolos de intervención. Nuestro objetivo inicial consistirá en analizar los modelos punitivos que inspiran cada uno de ellos, subrayando las discrepancias existentes en materia de procedimientos, técnicas de indagación, formas de explicación y prueba, así como de los grupos profesionales involucrados. Posteriormente, nos centraremos en las repercusiones ocasionadas por la "penalidad de la norma" en la maquinaria judicial del siglo
XIX. ¿Cuál es el marco sociopolítico que explica la llegada de una penalidad en la que el delito, sus causas y su enjuiciamiento, quedan comprendidos en el marco de categorías elaboradas en las ciencias positivas, no en el Derecho? ¿Supone la desestabilización del poder judicial y por tanto la debilitación del Estado? ¿O se trata más bien de la extensión del poder judicial y de su maquinaria punitiva, por cuanto se inauguran formas novedosas de intervención judicial sin necesidad de que haya conducta delictiva?

Analizaremos estas cuestiones inspirándonos en las ideas de Michel Foucault y en los trabajos realizados por autores posteriores, cuyas obras refuerzan y continúan (no sin cierta crítica) las sugerencias realizadas por el primero. Adoptaremos un punto de vista teórico, no sin antes justificar nuestras afirmaciones por medio de documentación histórica pertinente. Esta estrategia conlleva desde luego costes que son inevitables: la generalización apresurada, el descuido de las variaciones, o incluso la ceguera analítica ante los desajustes o las pervivencias locales. Sin embargo, también existe (Garland, 2005, p. 10) una serie de beneficios asociados: como identificar las tendencias de conjunto que dominan el campo de las racionalidades punitivas, o bien señalar las dinámicas sociales en las que se enraízan las racionalidades punitivas, esto es, la manera en que las finalidades y las medidas del campo del control del delito mantienen analogías con mecanismos de regulación social más amplios, como el gobierno a través de los expertos, la provisión de la asistencia social o el correccionalismo punitivo.

\section{EL HOMO PENALIS O EL PENALISMO UTILITARISTA}

De las muchas referencias que caracterizan a la teoría del Derecho penal, ninguna tan recurrente como el principio de legalidad formulado por Anselm von Feuerbach. En él aparecen condensadas, si bien de manera implícita, las garantías que rigen el desarrollo de la justicia penal en los Estados modernos. La ley, el crimen y el castigo quedan así articulados por una teoría de la pena que hace de la coacción psicológica (vale decir, disuasiva) la prevención básica del crimen. El brocardo es de sobra conocido: nulla poena sine lege, nulla poena sine crimine, nullum crimen sine poena legali. Que se puede desbrozar como sigue:

Nulla poena sine lege: solo hay pena sobre la base de la ley vigente, esto es, no hay delito o contravención penal sin ley. Esta última no puede aplicarse a hechos perpetrados en un momento 
previo a la entrada en vigor de la ley ${ }^{1}$. Al contrario, es la ley la que, dentro de la teoría clásica, instaura un momento fundacional, como si la conducta delictiva no preexistiera a las definiciones legales de la criminalidad. Todo ello encuentra una fuerza suplementaria en la teoría de la pena como coacción psicológica: si el objetivo pasa, como dice Feuerbach, y antes Beccaria ${ }^{2}$, por desempeñar una función inhibidora del impulso delictivo, la ley debe preceder a la conducta delictiva.

Nulla poena sine crimine: no hay castigo si no hay delito. Es decir, el sistema jurídico debe demostrar la existencia de un acto criminal, tipificado como tal en un marco legislativo que le precede. Tal cometido recae en la magistratura, cuya función es especificar los hechos que son constitutivos de delito y dirimir, mediante un juego de convenciones explícitas de "prueba" y "hecho", la culpa y la responsabilidad del delito.

Nullum crimen sine poena legali: no hay acto criminal sin pena legal. El delito consiste en una infracción definida por la ley. Por tanto, se prohíbe el intento de crear delitos o sanciones penales amparándose en el Derecho consuetudinario o en la costumbre. Así la única fuente del Derecho penal es el criterio legislativo, no la tradición. Las sanciones solo son legítimas si se han formulado y aplicado según las formas previstas por la ley.

La conclusión es inequívoca: tales máximas son el fundamento del Derecho penal y del garantismo moderno. Pero también son la constatación de que los Estados modernos hacen del Derecho su fundamento y su medio de acción, ya que configuran una comunidad política donde la actividad jurídica y administrativa (y entre ella, la penal) queda contenida, sin riesgo de interpretaciones arbitrarias, en la formulación propia de la ley ${ }^{3}$, esto es, en un ordenamiento jurídico que prescribe los elementos necesarios para que la labor judicial sea automática, de mera aplicación, eliminando así el poder judicial arbitrario.

Se podrían profundizar estas reflexiones, pero desviando el propósito inicial del presente trabajo. ¿Por qué comenzar entonces con esta máxima?

\footnotetext{
Véase el artículo 8, Declaración de los derechos del Hombre y del ciudadano (1789).

2 En Beccaria, mucho antes que en Feuerbach, se encuentran algunas indicaciones sobre la necesidad de que la pena tenga una función disuasoria. Véase, en concreto, el capítulo XV de Beccaria (2002, pp. 68-71).

3 Afirmaciones similares se pueden encontrar en los reformadores de la época. Véase, por ejemplo, Servan (1768, pp. 52-53), Beccaria (2002, p. 47). Pero también en los artículos v y VII de la Declaración de los derechos del Hombre y del ciudadano de 1789.
}

Porque a pesar de su relevancia, la teoría clásica revela una ausencia sintomática, pues su modelo de penalidad sigue limitándose a retribuir grados de responsabilidad, no a castigar sujetos de acuerdo con la naturaleza subjetiva del infractor. Se elude así lo que Pascale Pasquino (1991, p. 237) llama la figura del homo criminalis. Y con él, todas las formas de castigar y enjuiciar el delito sustentadas en el marco de categorías de procedencia extrajurídica. En su lugar la teoría clásica postula el principio del "libre albedrío", que funciona como fundamento de imputabilidad jurídica, pero también como presupuesto que convierte a la reacción penal en un reproche con contenido moral (Hierro, 1989, p. 168). Para ver estas cuestiones no es preciso la exposición detallada de la filosofía clásica, pero sí el recuerdo de los principales presupuestos que han sustentado las prácticas y los procedimientos de la penalidad clásica y ello nos permitirá comprender la crítica planteada por criminólogos y juristas de finales del siglo XIX a la jurisprudencia clásica. Recordaremos sus premisas más célebres:

1. El postulado del libre albedrío y la responsabilidad: en la doctrina clásica, el libre albedrío funciona como el fundamento de imputabilidad. El juez, cuando enjuicia a un sujeto y le impone una pena prevista por la ley, considera al imputado como un ser libre y racional (Carrara, 1887, p. 38). Sin libertad, sin capacidad de tomar decisiones y, eventualmente, llevarlas a cabo, sería difícil poder juzgar a una persona. De hecho, la posibilidad de que un individuo pueda ser sujeto de responsabilidad jurídica, es algo que depende, en gran medida, de su facultad de dañar o no. Por tanto, es el libre albedrío el que funda la posibilidad de exigir una indemnización a una persona por el daño ocasionado por sus actos. El marco clásico se ampara así en el supuesto de que los seres humanos, en condiciones normales, son capaces de conocer y de valorar el deber de respetar la ley, así como de entender y conocer los daños que sus acciones pueden ocasionar en los intereses de sus semejantes.

Esto no siempre funciona así, ya que se puede dar el caso de que haya acciones que o bien se cometieron sin discernimiento, como sucede con los dementes ${ }^{4}$ o los menores, o bien se produjeron en circunstancias eximentes, al considerar que el imputado actuaba coaccionado o en estado de

\footnotetext{
4 Si bien la demencia se reconocía como un motivo invocado desde el Derecho romano, este supuesto no aparece, de manera formal hasta el Código penal napoleónico, en su artículo 64 .
} 
necesidad ${ }^{5}$. Para tales casos, la penalidad clásica contempla la inimputabilidad jurídica, lo cual no hace sino corroborar lo ya dicho con antelación. Es solo el libre albedrío, la capacidad que tiene un sujeto de actuar con libertad y conciencia de los daños que sus acciones pueden ocasionar, lo que le convierte en un sujeto imputable, en alguien que tiene la facultad de ser culpable. Y por eso el libre albedrío también es el fundamento que reviste a la reacción penal de una amonestación moral. Al ser un sujeto libre de sus actos, la punición encuentra su justificación en la existencia de una decisión previa. El sujeto decide, por así decirlo, si continua el impulso de sus deseos, aun cuando ello comporte el daño ocasionado a sus semejantes, o si se decanta por el respeto de las leyes. En esta posibilidad de elección consiste la libertad que hace de él un sujeto moral y, por tanto, un sujeto responsable en términos penales.

2. El postulado de la proporción entre los delitos y las penas: en la doctrina clásica, este principio se encuentra supeditado a la finalidad preventiva que anima el sistema jurídico liberal. Dicho principio buscó erradicar el sistema penal que hacía posible la discrecionalidad de los jueces en cuanto a la elección de las penas, proponiendo un sistema de penas tarifadas en función de la gravedad de los delitos. Beccaria (2002, pp. 8688) formula por vez primera este postulado y le otorga un papel estratégico en la lucha contra el sistema penal y procesal de la época, de carácter inquisitorial.

Merece la pena, por su valor ilustrativo, recordar el argumento de la proporción entre los delitos y las penas. En efecto, Beccaria, al igual que la filosofía contractualista, vincula el origen de la función punitiva al origen y el fundamento del poder político: es decir, la necesidad que funda la constitución de la sociedad es la misma que justifica el mal necesario de las penas (ibíd., pp. 45-47). Dado que los delitos no afectan de igual modo a la estabilidad del orden social, es indispensable, con la vista puesta en la prevención disuasora, articu-

\footnotetext{
5 La posibilidad de modular la pena en función de circunstancias atenuantes no es un rasgo exclusivo del paradigma positivista. También se encuentra en la jurisprudencia clásica, si bien de una manera diferente. Así, mientras que este último fundamenta la modulación de la pena en el análisis de la personalidad del acusado, la jurisprudencia clásica lo hace basándose en el análisis de las circunstancias del acto. Así deben entenderse las reformas de la legislación penal que tuvieron lugar en Francia entre 1824 y 1832, que concedían al juez (y después al jurado) la posibilidad de modular la pena sobre las circunstancias de los actos. Véase Guignard (2007, p. 159).
}

lar una escala de penas adecuada a la gravedad del daño social infligido por cada acto delictivo. Debe haber pues una proporcionalidad entre los delitos y las penas: el castigo debe ser más fuerte a medida que los delitos sean más contrarios al bien público (ibíd., p. 86). Porque de no ser así, se corre el riesgo de imprimir una sensación menos eficaz y disuasiva sobre las representaciones de los individuos. Si ante dos delitos diferentes se aplica una misma intensidad de la pena, los sujetos tenderán a inclinarse por el mayor delito, pues encuentran unido a él un mayor beneficio. El mal de la pena debe exceder al bien que nace del delito, pero si ese mal es idéntico para aquellos delitos que ofenden de manera desigual al orden social, la funcionalidad de la pena pierde su eficacia preventiva, produciéndose así una situación en la que el valor final del bien (placer) derivado de la comisión del delito prevalece sobre el valor final del mal (dolor) asociado a la pena.

Por eso, lo ideal es traducir la gravedad del delito a una escala correspondiente de penas, siendo la dureza de estas directamente proporcional al daño social producido por cada especie de delito. A mayor daño, mayor cantidad de pena, y así escalonadamente. Pero en este cálculo no se considera la psicología del infractor: es el daño público, definido en abstracto, lo que determina la medida de la pena, no la sensibilidad del reo (ibíd., p. 92). El castigo es, por tanto, jurídico, así como las reglas que califican la gravedad del delito. Lo juzgable no es el riesgo de criminalidad esbozado por la personalidad del infractor, sino las infracciones efectivamente reprimibles, tal como aparecen en los códigos jurídicos. Todo lo demás resulta incompatible con la antropología utilitarista y el fetiche del actor racional, ambos aspectos fundamentales de la doctrina penal de los reformadores.

3. El postulado de la uniformidad de las penas es una derivación del principio de igualdad establecido por la doctrina clásica. Según esta, el Derecho penal debe ser compatible con una teoría de la obligación política que justifica sus restricciones conforme a los valores de libertad y autonomía individual. Por ello, el Derecho penal debe juzgar al margen de las desigualdades de trato y de las prerrogativas derivadas de la estructura estamental de la sociedad. Las penas, por así decirlo, deben ser las mismas para todos, con independencia de cuál sea el capital simbólico (honor estamental) o material del sujeto (ibíd., p. 92). En efecto, si el ser humano nace igual en cuanto a sus derechos, la ley penal debe aplicarse de la misma manera a los individuos. La uniformidad 
del castigo es la consecuencia de la proporcionalidad de la pena, de los derechos individuales y de la igualdad jurídica que se colige de la teoría del contrato social (Garland, 2018, p. 138). Es una medida que, amparándose en la idea de que el acusado es un sujeto portador de razón y libertad, un ciudadano a quien le corresponde recibir igual trato ante la ley, busca proceder mediante una fórmula de castigo basada en un sistema uniforme de técnicas y de condiciones aplicables a todos los reclusos, con independencia de su tipología delictiva y su biografía individual.

Como todos los individuos nacen libres, iguales, racionales y responsables, el Derecho penal debe juzgar y castigar de acuerdo con tales características. El modo de hacerlo es instalando un régimen de castigo en el que se busca la uniformidad a través de la reglamentación rigurosa de las condiciones de vida. Existen numerosos ejemplos dentro de esta perspectiva: el recurso creciente al encarcelamiento ${ }^{6}$; la construcción de prisiones celulares, donde se confina a cada preso en celdas de dimensiones estandarizadas e idénticos equipamientos; la imposición de una dieta uniforme; la obligación del trabajo forzado; el uso de uniformes para los reclusos; la imposición de una educación religiosa; y, por último, el sometimiento a un régimen de disciplina consistente en homogeneizar el tiempo del reo mediante la imposición de un silencio absoluto y su escisión por los ritos de las prácticas penitenciarias (trabajo, oración, alimentación, visitas de carácter moral o religioso, ejercicios, etc. $)^{7}$. Tales elementos fueron objeto de cálculo por parte de numerosos informes y escritos oficiales ${ }^{8}$, lo cual atestigua una preocupación clara por uniformizar las condiciones del castigo

\footnotetext{
${ }^{6}$ Decimos creciente porque la sentencia a prisión, en la primera mitad del siglo XIX, tenía que competir con otras formas de pena (la deportación, la pena capital, los azotes o multas). Para Inglaterra, véanse las cifras de Rusche y Kirchheimer (2004, pp. 123-124).

7 La preocupación por un régimen de vida uniforme se materializó en la prisión de Pentonville. Creada en 1842 se convirtió en un modelo para la construcción y/o la reforma de otras prisiones en Inglaterra y en Europa. Véase Ignatieff (1978, pp. 3-15 y 195-200). En Francia, cabe mencionar el caso de La Petite Roquette, donde también se instauró un sistema de aislamiento celular para los jóvenes adolescentes (Perrot, 2001, p. 197). En Estados Unidos, se puede recordar la prisión de Cherry Hill, en Filadelfia.

8 Para la Inglaterra victoriana, véanse el Informe Carnarvon (1863), el Informe del Comité sobre dietas (1878), la Ley de Prisiones de 1865, etc. Para el caso francés, véase la circular Montalivet (1839), o la circular Duchatel (1841), que prescribe la adopción del modelo celular para las prisiones departamentales.
}

en el interior de las prisiones. Cada preso era tratado como un individuo más, conforme a un sistema retributivo cuyo cálculo no estaba motivado ni por la tipología delictiva ni por las previsiones de peligrosidad asociadas a la biografía del reo. Esta uniformidad era compatible con criterios de clasificación interna: los presos, como recuerda Garland (2018, p. 50), seguían clasificándose en función de la edad, el sexo o la duración de la pena. Pero esas clasificaciones no se traducían ni en diferentes condiciones de castigo ni en tratamientos punitivos diferentes ${ }^{9}$; al contrario, su propósito era administrativo, lo cual dejaba traslucir la preminencia de una concepción jurídico-formal de la culpabilidad, basada en hechos imputables y no en diagnósticos referentes al riesgo representado por la personalidad del infractor. En resumen, era un modelo que reconocía individuos, pero no individualidades (ibídem).

Cabe entonces plantear las implicaciones que se desprenden de estos postulados, especialmente en lo que se refiere al delito, el castigo y el infractor. En efecto, ¿cómo se concibe, desde la doctrina clásica del Derecho penal, la naturaleza de estos conceptos? Algo de esto ya se ha sugerido, aunque parece oportuno complementarlo con una serie de reflexiones añadidas. Así, para la doctrina clásica el delito es ante todo un ente jurídico (Carrara, 1859, p. 10), un objeto construido por la definición que la norma penal realiza de un acontecimiento de la vida humana (Rivera, 2011, p. 45). En sentido estricto, lo delictivo no preexiste a la definición legal de criminalidad; esta última hace posible, por medio de la dogmática jurídica, que los hechos humanos se puedan traducir en índices constitutivos de delito. Así, lo delictivo no es una propiedad inherente a los hechos, es una cualidad que los hechos adquieren al ser investidos por criterios de abstracción lingüística. El Derecho funciona como un filtro que reordena conceptualmente la realidad, ya que construye formas de visibilidad capaces de percibir entidades (delitos) ahí donde antes (de la formulación del Derecho) solo se percibía dispersión (estado natural). Sin esa maquinaria, sin ese dispositivo que impone un orden arbitrario y establece convenciones para

\footnotetext{
9 En España existen numerosas normativas que regularon la separación interna de los reos, si bien son clasificaciones que no atienden a criterios de individualización científica y sistemas progresivos. Véanse los Reglamentos de Presidios peninsulares de 1807, las Ordenanzas de las Audiencias de 1835 o la Ley de Prisiones de 1849. Véase Figueroa Navarro (2000, pp. 48-49).
} 
interpretar los hechos, el delito no podría existir como entidad jurídica y, consecuentemente, el Derecho no podría disponer de objetos con los cuales edificar sus casos, utilizando reglas procesales, procedimientos técnicos de prueba, etc.

Algo parecido se puede argüir en cuanto al estatus o la naturaleza del castigo: queda comprendido como un hecho jurídico. Lo específico de la doctrina clásica es que los procedimientos que utiliza para sancionar y condenar a los transgresores dependen de formas de explicación y de prueba elaboradas en el ámbito de la dogmática jurídica. El Derecho y su concepción jurídico-formal de la culpabilidad impregnan la lógica y las clasificaciones de los procedimientos legales. Se considera al delito, sus causas, su enjuiciamiento y su castigo en el marco de los términos del Derecho (Garland, 2018,p. 55). Así, lo penal y lo jurídico son, para la doctrina clásica, términos con una extensión idéntica. Lo cual, en parte, tiene sentido, ya que los reformadores pretendían fundar el Derecho penal al margen de la discrecionalidad que caracterizó a los juicios en el Antiguo Régimen. Pero al hacerlo así también encorsetaron el enjuiciamiento en el interior de un esquema técnico y abstracto, construido sobre la base de reglas procedimentales que lo convertían en un objeto procesal diferente del objeto del litigio vivido. Y dominado, debido a ello, por la existencia de un orden impersonal que somete las intervenciones de las partes a la criba del saber culto y a la mediación de abogados que litigan en torno a la responsabilidad del acusado, según una serie de convenciones y disposiciones legales aplicables.

Este legalismo también caracteriza al objeto de castigo, al delincuente. Para la doctrina clásica, el delincuente no es una especie separada, es un infractor (homo penalis) de la ley penal, por tanto, un sujeto a quien le corresponde una voluntad libre, racional y responsable. Si el Estado decide castigarle, lo hace por incumplimiento contractual, sin necesidad de invocar una anomalía patológica que justifique su demanda de castigo. Pero por paradójico que resulte, el delincuente es también el sujeto del contrato: define su condición desviada a partir de la relación conflictiva que mantiene con las obligaciones del acuerdo contractual. El Estado interviene sus derechos no porque su ser represente una anomalía que escapa a su control, sino solo porque incurre en una circunstancia ilegal (nulla poena sine lege). En este sentido, el delincuente es un sujeto constituido de manera similar al ciudadano que cumple la ley: ambos son libres y racionales (Garland, 2018, p.
143). Pero mientras uno decidió, en cierta ocasión, desplegar una conducta delictiva, sopesando el valor que su acción podía reportar, el otro optó sin embargo por no hacerlo. Y en esa divergencia, la doctrina clásica no ve una diferencia de naturaleza, tan solo una confusión de representaciones, un desajuste en el cálculo que el individuo realiza de sus placeres y sus dolores.

En suma, para la doctrina clásica cualquier sujeto puede cometer un delito: lo que distingue a un infractor de un no-infractor no es una diferencia de naturaleza, es un suceso contingente. Es la decisión de un sujeto -errónea, sin duda, pero "libre" y consciente- que no ha sabido calcular el valor final del dolor que su acción podía reportarle, representando erróneamente el valor inmediato de su placer. El homo penalis existe así como una potencialidad en cada sujeto: pero solo se actualiza a través de las violaciones de la ley que cualquiera puede cometer como resultado de un cálculo erróneo (Pasquino, 1991, p. 238). La acción delictiva no es el producto de un sujeto que actúa bajo la presión de factores que escapan a su control, sino el resultado manifiesto del mal uso de la razón. Es la razón y el cálculo instrumental lo que capacita a los seres humanos para preguntarse por el tipo de beneficios o de perjuicios que pueden resultar de sus acciones; por tanto, son ellos, según la doctrina clásica, quienes deben prever los efectos beneficiosos o negativos que pueden obtener si actúan de cierto modo o de otro. Ocurre sin embargo que, por una confusión o un cálculo erróneo en el orden de las representaciones, el individuo despliega conductas (mercantiles, delictivas, etc.) cuyas ventajas no exceden a las desventajas finales asociadas a las mismas. Hay individuos por ejemplo que, debido a un cálculo rápido de beneficios, se inclinan por la comisión de un delito porque asocian la realización de este a la satisfacción de un bien (placer) inmediato, sin reparar en el mal o los costos finales (dolor) que su acción podía reportarle.

Pero ya sea un delincuente o un ciudadano que cumple la ley, ambas acciones responden al mismo esquema de conducta humana. Ambos tienen como motor básico la búsqueda del placer y el repudio del dolor. Bentham sitúa esta antropología en el interior de la concepción disuasoria de la pena, justificándola y dándole una fuerza de evidencia apriorística. Todo individuo, dice, se comporta conforme a un cálculo de dolores o de placeres. Si anticipa que un dolor será la consecuencia de un acto que le agrada, esta idea se imprimirá en su conciencia y le desalentará de esa acción. 
Y si además es capaz de prever que el valor total del dolor excede al valor total del placer, la fuerza repulsiva será mayor. Por tanto, el acto terminará por no producirse (Bentham, 1826, pp. 15-16).

Tal razonamiento opera en la lógica de la racionalidad punitiva clásica. Todo sucede (Pasquino,1991, p. 239), como si el encarcelamiento fuese una consecuencia similar a quien sufre una bancarrota, esto es, el resultado de malas decisiones o de una falta de anticipación racional del individuo. La ilegalidad se contempla como un efecto de la elección individual y de un cálculo erróneo, al igual que la pobreza (Garland, 2018, p. 54). La antropología que sirve para explicar la acción del homo penalis es la misma que explica la conducta del homo economicus. En el fondo, todo se reduce a una teoría general del ser humano que postula la libertad abstracta y el fetiche de un sujeto calculador dedicado a la búsqueda del placer y el repudio del dolor. Por supuesto, es fácil advertir aquí una conexión clara entre la racionalidad punitiva clásica y la psicología utilitarista liberal. Los supuestos que vertebran el enjuiciamiento penal son en realidad las transcripciones jurídicas de los postulados utilitaristas del liberalismo económico. El delincuente no es una especie nueva, sino un ser dotado de una naturaleza racional, lo mismo que el propietario o el ciudadano que cumple la ley. El hecho de no actuar conforme al Derecho no le desliga de su condición racional, pero sí manifiesta un fallo en cuanto al cálculo de las consecuencias resultantes de sus acciones.

De ahí la importancia de la disuasión y la retribución. Ambos aspectos han inspirado los sistemas punitivos clásicos. Si el delincuente es un sujeto racional que se mueve erráticamente en la búsqueda del placer, la disuasión es la herramienta que utiliza el Derecho penal para negar la utilidad del delito. La disuasión sirve para prevenir la confusión de representaciones y evitar que el individuo tome el placer inmediato como guía primera de la acción. Por eso, dice Garland (ibíd.), la estrategia de disuasión siempre queda expresada en criterios vinculados a la menor elegibilidad. La dieta, la higiene, el trabajo (forzado) o la disciplina fueron medidas destinadas a disuadir la sensibilidad de los reos potenciales, a fin de hacerles creer que el mal surgido de la pena (el duro régimen de vida) siempre excede al bien que nace de la comisión del delito. Lo mismo se puede decir de la retribución, traducida en un sistema de confinamiento destinado a reconstruir el contrato social mediante un castigo proporcional.
Deben verse aspectos como la arquitectura carcelaria o los regímenes disciplinarios, basados en el confinamiento solitario (modelo de Filadelfia) o en el sistema mixto (modelo de Auburn), ante todo como un medio de enfatizar el mensaje de la responsabilidad individual. Mediante el aislamiento y la disciplina, el reo tomaba conciencia de los términos paradigmáticos de lo que "debería ser" la sociedad libre (Pavarini y Melossi, 1980, p. 196). Todo funciona con el objeto de restaurar un sujeto jurídico caído: el diálogo constante consigo mismo y el automatismo de los hábitos se convierten así en instrumentos para inducir al reo a concienciarse de su responsabilidad individual, al tiempo que se hace de él un sujeto obediente.

Hasta aquí algunos aspectos relativos a la penalidad de la ley: se trata de un modelo retributivo, basado en la idea de que la responsabilidad es una consecuencia del libre albedrío y del sujeto racional. Por eso, la responsabilidad penal obedece a la ley del todo o nada. $\mathrm{O}$ se es responsable, $\mathrm{o}$ simplemente no se es (Guignard, 2007, p. 158). Y en esta dicotomía no cabe indagación alguna que trascienda la causa final de los actos. Para que la justicia funcione es preciso que existan criminales "responsables", por paradójico que resulte.

\section{CUANDO EL LIBRE ALBEDRÍO NO ES LIBRE: LA IRRUPCIÓN DEL HOMO CRIMINALIS}

Hay otra forma de racionalidad punitiva, surgida como consecuencia de la colonización del espacio jurídico por parte de las teorías alienistas y los programas de acción criminológicos. En efecto, la evolución del complejo penal, especialmente desde finales del siglo XIX, representa un cambio significativo en el orden de las racionalidades punitivas. Las sanciones, las técnicas de indagación, los grupos profesionales involucrados, comenzaron a esbozar un patrón diferente de relaciones mutuas, con esquemas de acción y registros discursivos novedosos. No fue una estrategia premeditada ni un fenómeno que se gestara en el interior del Derecho penal. Su aparición resulta más bien de la confluencia de una serie de teorías y programas de prevención penales que no responden ni a la misma cronología ni a la misma promoción de grupos profesionales (antropólogos, psiquiatras, directores de prisión, etc.). Cabe buscar aquí la complementariedad entre la ley y la norma, no como elementos antitéticos sino coadyuvantes.

El alienismo y el primer programa criminológico suministraron importantes recursos para la configuración de la nueva racionalidad punitiva de 
carácter etiológico. La proliferación de entidades nosográficas como las monomanías homicidas, de origen psiquiátrico, así como el desarrollo de anomalías morales, utilizadas por los criminólogos, justificaron la necesidad de estrategias penales de tipo no retributivo. Tales términos demoraron un tiempo en implantarse, pero finalmente acabaron por hacerlo, no sin antes librar una dura batalla entre los diversos grupos profesionales que pugnaban en las salas de justicia ${ }^{10}$. No podemos narrar este proceso desde la perspectiva histórica, pero sí poner de manifiesto algunos cambios suscitados en el interior de la maquinaria penal. Cambios que contrastan con los postulados y las estrategias de regulación del delito planteadas por los reformadores clásicos. Conceptos como "culpa", "proporcionalidad" o "uniformidad de las penas" fueron desplazados en beneficio de una intervención penal preocupada por la naturaleza subjetiva del infractor. El objetivo no era retribuir grados de responsabilidad, sino adoptar aquellas medidas que, con mayor seguridad, prevén la evolución más adecuada (más personalizada) del sujeto infractor y, por tanto, la corrección de los rasgos que han motivado su ingreso en prisión.

No obstante, además de precisar las sanciones y los grupos profesionales que promueven este programa, conviene subrayar el modo en que la nueva racionalidad punitiva cuestiona el núcleo del clasicismo. Para ello hay que remontarse a los argumentos utilizados por la scuola italiana (Ferri, Garofalo) y algunos de los principales juristas penales (Saleilles, Prins, Liszt) del momento: ahí encontraremos las pistas que delimitan los contornos de la nueva racionalidad punitiva.

1. En primer lugar, la crítica del libre albedrío y la idea de responsabilidad: utilizando argumentos extraídos de las ciencias fisio-psicológicas, Ferri (2004b, p. 4) insiste en que el libre albedrío es una pura ilusión subjetiva, originada en el desconocimiento que tienen los seres humanos de los antecedentes (fisiológicos o psíquicos) que concurren en la deliberación previa a la voluntad. La fisiología y la psico-patología (ibíd., p. 8), muestran que "la voluntad humana está completamente sometida a las influencias naturales, no solo de orden moral o psicológico, sino también de orden puramente físico". Idéntica función cabe atribuir a la estadística criminal o demográfica, cuyos da-

\footnotetext{
${ }^{10}$ Las luchas entre juristas y psiquiatras en torno a la (des) responsabilidad del delincuente fueron numerosas. Para el caso español, véanse los estudios de Campos (2007), Álvarez-Uría (1983: 181-243), Huertas (2006). Para el caso francés, Georget (1825) y Foucault (1973b).
}

tos revelan la dependencia en que se encuentran las acciones voluntarias (matrimonios, suicidios, delitos) con respecto a las variaciones del medio físico y social (ibíd., p. 12). La conciencia de ser libres de querer una cosa mejor que otra no es prueba de su veracidad (ibíd., p. 4). Al contrario, si algo ponen de manifiesto las ciencias de la época, desde la psicología positiva a la estadística moral, es el carácter de situación impuesta (objetivamente estructurada) desde el cual se elabora la vivencia individual. Los fenómenos mentales no pueden explicarse únicamente por medio de las representaciones conscientes que los individuos tienen de su experiencia de la acción. Por debajo existen ciertas determinaciones -ejercidas, pero no representadas- que no pasan por el reconocimiento previo de un sujeto, y que sin embargo predisponen a los individuos a tener probabilidades objetivas desiguales (mayor o menor propensión al delito, al suicidio, al matrimonio, etc.).

De acuerdo con esto, el libre albedrío es una ilusión subjetiva. Hay que ver la conducta humana como el resultado de las determinaciones sociales, psicológicas y biológicas, y no como un hecho ejecutado en virtud de un marco puro de actividad lógica. He aquí el punto de partida de la escuela criminal positiva, también una innovación no exenta de consecuencias desde el punto de vista jurídico. Si el libre albedrío es ilusorio, si es sustituido por el determinismo de las ciencias positivas, que defiende que la criminalidad de un sujeto no es el resultado de un acto libre y consciente, sino de un ser que actúa bajo la presión de influencias que escapan a su control, entonces la idea de culpa o responsabilidad caen bajo la misma sospecha. $\mathrm{O}$ al menos dejan de estructurar el ejercicio penal en los términos en lo que lo había hecho la jurisprudencia clásica.

La segunda consecuencia está íntimamente relacionada con la anterior, de hecho, es su presupuesto necesario. Si la criminalidad de un sujeto no proviene de un acto libre y consciente, si el delincuente actúa presionado por "deformaciones" que escapan a su control, entonces el criminal resulta un tipo antropológico diferente. Es un sujeto al que las "anomalías orgánicas y psíquicas, hereditarias y adquiridas, lo convierten en una clase especial, en una variedad de la especie humana" (Ferri, 2004a, p. 46). Un sujeto que actúa a expensas de su naturaleza anormal, siendo esa anormalidad la causa primera de su delito y de su incapacidad moral para cumplir o adaptarse a los modos de vida de la sociedad en la que vive. Así, sin llegar al extremo de negar el influjo de 
las causas sociales, lo cierto es que la scuola positiva explica la conducta criminal como un acto que responde a un elemento congénito diferencial (Garofalo, 1885, p. 126). No quiere esto decir que las causas sociales se destierren del análisis criminológico, más bien se ven desplazadas en cuanto a su alcance explicativo. Si se aceptan, es solo porque desempeñan un papel inhibidor o revelador de la criminalidad, pero no una causa determinante. Es decir, el medio social puede variar las cifras del crimen, pero la disposición criminal existe como una diátesis, como algo inscrito en el propio sujeto (ibíd., p. 126). Da igual si esa latencia se enraíza en el cuerpo (prognatismo, asimetría craneal, etc.) o en la mente (imbecilidad moral, manía persecutoria, monomanía homicida, etc.), el hecho es que cada vez cala más la idea (no solo en la ciencia penal sino también en la legislación) de que el delito es provocado por factores que escapan al control volitivo del individuo.

Se abre así paso un nuevo objeto de ciencia y práctica penal: el homo criminalis. Surgido al calor de la medicina alienista, esta figura ganó terreno en la esfera de la práctica y el pensamiento penal, inspirando leyes y sanciones que auguraron el advenimiento de una nueva racionalidad punitiva, caracterizada por el descentramiento de la prisión, la apertura de centros terapéuticos y la individualización de las penas. Así, a diferencia del pensamiento penal clásico, el delincuente se presenta ahora desde una perspectiva determinista. La razón del crimen hay que buscarla en el "carácter criminal" o la "criminalidad" personal, no en un cálculo erróneo de representaciones. La conducta delictiva (sobre todo, la reincidente) no es una simple violación de las leyes positivas, es ante todo la expresión de una entidad patológica distintiva, el llamado "carácter criminal". El problema es que una apelación como esta, fundada en el axioma de que existe una entidad congénita diferencial, es más una proclamación que una demostración empíricamente contrastada. Si bien se realizaron múltiples análisis de los rasgos fisionómicos y psicológicos de los detenidos, encontrando una serie de estigmas en sus cuerpos y sus conductas, tales rasgos, a pesar de ser frecuentes, entraban en el espectro de variación normal de las poblaciones humanas (Garland, 2018, p. 147). Además, del análisis de los rasgos anatómicos se deducían conclusiones que hoy serían difícilmente sostenibles, como la insensibilidad moral, la falta de remordimientos o la tendencia impulsiva, características todas ellas que permitirían explicar y prever (criminalizar) de antemano conductas delictivas (Ferri, 2004a, p. 59).
Tal es la razón de que ciertos analistas contemporáneos, como Garland (2018, p. 147), sostengan que la criminalidad, entendida al modo lombrosiano, esto es, como un "carácter criminal" innato, sea en realidad un constructo metafísico tan gratuito como el "libre albedrío". Más que una entidad objetiva, aislable y manipulable, la "criminalidad" es una inferencia construida a partir de la sobrestimación de la frecuencia de ciertos rasgos anatómicos encontrados en los detenidos, los cuales también se observan en poblaciones no criminales ${ }^{11}$. Esta ceguera se debe en gran medida, aunque no exclusivamente, a que se ha constituido el positivismo criminológico con miras a su aplicación práctica inmediata. También a los problemas en la medición del comportamiento, pues estaba obligado a distinguir el delito y la conducta desviada del comportamiento normal sobre una base cuantificable.

2. Pero además del cuestionamiento del libre albedrío, los argumentos indicados también conllevan una crítica del postulado de la proporcionalidad de las penas. Si el libre albedrío es una realidad ilusoria, también lo es el propósito de organizar la práctica penal a partir de los términos de culpa $\mathrm{o}$ responsabilidad. El hecho de afirmar que se ha descubierto una criminalidad inscrita en los cuerpos hace imposible medir la justicia en función de unos términos que siguen presuponiendo la existencia de un acto libre y consciente. El mal de la pena siempre debía exceder al bien que nace del delito (Beccaria, 2002, p. 69). Tal era la lógica que subyace a la jurisprudencia clásica, una lógica donde lo relevante, como apunta Garofalo (1885, p. 90), es la determinación de los caracteres exteriores de

\footnotetext{
${ }^{11}$ Pese a ello, el programa criminológico siguió postulando la existencia del «carácter criminal»o «criminalidad». Se debió a cuestiones relativas a la supervivencia de su propio espacio discursivo e institucional. Sin la existencia de una entidad gnoseológicamente definida («criminalidad»), se desvanecía la posibilidad de conquistar un espacio lógico e institucional, ya que se carecía de un dominio particular de objetos. Tal es el límite de esta nueva criminología asumida como científica: al no tener por objeto el delito considerado como concepto jurídico, sino al delincuente como un individuo diverso y, en cuanto tal, como clínicamente observable, pierde sentido el principio de legalidad. Y este desplazamiento del foco del delito al reo supone una potenciación del margen de discrecionalidad de los campos propios de las ciencias sociales y médicas, cuya eficacia se medirá no solo por individualizar los factores que determinan el comportamiento criminal sino también por su eficacia para combatirlos con medidas que tienden a modificar al delincuente a través de una concepción positivista de la ciencia.
} 
los delitos, así como su clasificación atendiendo a criterios puramente jurídico-formales: los derechos que se lesionan, la indagación de la pena justa y proporcional en abstracto, etc.

Por el contrario, a raíz de las ciencias antropométricas y los peritajes psiquiátricos, la práctica penal empezó a experimentar una mayor sensibilidad por la biografía del delincuente y las medidas adaptadas a la personalidad delictiva. Hasta ese momento el Derecho penal procedía según una lógica que establecía penas fijadas por anticipado (Ferri, 2004b, p. 15). En ese esquema, la persona del criminal era un sujeto al cual se le aplicaban fórmulas teóricas, amparándose en el supuesto de que su acción delictiva lo convertía ipso facto en un sujeto responsable, debido a la determinación que libremente había tomado. Sin embargo, cuando este supuesto se tambalea, también lo hace la lógica retributiva que lo acompañaba. La responsabilidad moral se sustituye así por una responsabilidad de tipo social. Por eso el nuevo programa criminológico considera la pena como una prevención en favor de la defensa social, basada no tanto en la disuasión y la segregación del delincuente sino en su curación y su tratamiento individualizado. En esas circunstancias, la medida de la pena debe ser proporcional a la peligrosidad del delincuente, no a la gravedad de un delito considerado en abstracto y sin relación alguna con la personalidad del infractor (Baratta, 1986, p. 33).

La nueva racionalidad inaugura así un ámbito de problematización donde lo prioritario no es la reacción penal a lo que los individuos hacen, sino el control preventivo de lo que son capaces de hacer o están a punto de hacer (Foucault, 1973a, p. 97). El cambio es importante. En lugar de considerar al individuo desde la perspectiva de sus infracciones, el complejo penal inaugura estrategias punitivas motivadas por el riesgo de criminalidad representado por la personalidad del infractor. El acento se desplaza así del ámbito del crimen al del criminal, de los actos efectivos a las virtualidades del infractor. De modo que la pena, en vez de proceder a partir de la definición de la gravedad de los hechos punibles, actúa más bien a partir de la estimación que hacen los expertos sobre los detenidos, estableciendo una diferencia entre los criminales que "son definitivamente peligrosos y los que, mediante ciertos tratamientos, pueden dejar de serlo" (Foucault, 1996, p. 113). La peligrosidad se convierte así en la pieza maestra de la nueva maquinaria penal. Se trata de un término que, debido a su origen médico-jurídico, permite contemplar al delincuente como un enfermo y un criminal a la vez, sin que eso signifique ser totalmente uno u otro (Boullant, 2003, p. 93).

La peligrosidad no es un peligro real e inmediato, es una virtualidad inscrita en el organismo y la personalidad del infractor. Sustentada en los análisis de la antropología criminal y la medicina alienista, esta categoría permite movilizar una serie de estigmas o anomalías patológicas (locura moral, degeneración, monomanía homicida, etc.) como causas o fundamento del delito. Así, caracteres que no son en sí mismos infracciones, como la imprevisión, la imbecilidad moral, el prognatismo, la insensibilidad moral, la asimetría del cráneo, etc., se convierten sin embargo en indicios de criminalidad posible. Es como si el nivel de atención se hubiera desplazado del delito hacia el carácter del individuo. Así, el delincuente se convierte en algo más que un infractor ocasional; es un sujeto que actúa motivado por la tiranía inexorable de los impulsos que escapan a su control (Ferri, 2004a, p. 171). De ahí el carácter mitad jurídico, mitad médico, de la noción de peligrosidad. El individuo es peligroso no por la gravedad del delito cometido, sino porque la composición originaria de su constitución psíquica y orgánica hace que el delito se convierta en una disposición permanente en él.

En otras palabras, lo peligroso en el criminal no es el crimen cometido, sino el criminal mismo: es su persona, su temperamento siempre presto para sugerirle nuevos crímenes (Saleilles, 1923, p. 108). En sentido estricto, el crimen no desaparece, pero sí pasa a convertirse en un hecho que tiene valor como síntoma de "criminalidad" en el agente. Y como la criminalidad engendra siempre crimen, pero el crimen no siempre proviene de la criminalidad, la primera es la que debe ser objeto de tratamiento punitivo, siempre y cuando sea posible, y si no lo es, debe suprimirse al criminal, como se sacrifican a los animales peligrosos (ibíd., p. 109). El crimen es pues solo un hecho, la criminalidad un factor congénito que escapa al control del agente.

Surge así, en Derecho penal, la teoría de la defensa social, que postula la idea de que el peligro puede concebirse antes del propio crimen. Hay sujetos (delincuentes habituales, alcohólicos, anormales, vagabundos...) que sin necesidad de haber cometido delito alguno constituyen una amenaza para ellos mismos y para los demás, en razón de sus inclinaciones permanentes en contra del sentido social y moral ${ }^{12}$. Casos en los que la conduc-

\footnotetext{
${ }^{12}$ La preocupación por las inclinaciones permanentes también tuvo su traducción legislativa: en Bélgica, por ejemplo, se promulgó la ley de 1891 sobre los vagabundos, que permitía
} 
ta delictiva no es condición indispensable para justificar la intervención judicial (Prins, 2018, p. 46). La culpa deja paso a otros indicios que evidencian la supuesta condición de inimputabilidad del infractor, por cuanto revelan una incapacidad física o psicológica (la atrofia moral, según Ferri) para desarrollar el sentido y el cumplimiento de las normas sociales. En esos casos, la maquinaria penal aboga por un derecho que hace avanzar la penalidad más allá de los límites normales del Derecho penal clásico (Garland, 2018, p. 306). Un Derecho que no solo reacciona ante los actos delictivos, sino que garantiza el orden social a través de la asistencia y la higiene preventiva de los criaderos sociales del delito (Pasquino, 1991, p. 242).

Máxima pues de la nueva racionalidad penal: percibir un estado peligroso ahí donde aún no hay delincuente; justificar un derecho de intervención estatal donde todavía no hay crimen ni delito (Prins, 2018, p. 91). Se trata de un desplazamiento extraño (Boullant, 2003, p. 94), ya que el peligro (ausencia de sentido moral) jamás ha constituido un delito o materia de intervención judicial. Sin embargo, este personaje virtual, este sujeto infractor a la vez que necesitado, va a inspirar formas novedosas de intervención penal centradas en el control de los individuos al nivel de sus virtualidades ${ }^{13}$. Para ello se requiere un complejo de investigación (servicios de biología criminal, centros de evaluación psicológica, clínicas judiciales, oficinas de trabajo social, etc..$^{14}$ ) capaz de suministrar datos relativos a la historia biológica y psicosocial del delincuente, a fin de movilizar una serie de informaciones que el poder judicial puede utilizar para implementar programas de prevención de conductas antisociales.

Así, la génesis del "individuo peligroso" debe insertarse en una reconfiguración más amplia del complejo penal moderno, en virtud de la cual se

encerrarlos durante siete años debido a su inclinación permanente a la pereza y la holgazanería. Similares consideraciones parecieron inspirar la ley inglesa de ebrios de 1898, que contemplaba el encierro terapéutico sin necesidad de que se hubiera producido una infracción inmediata.

${ }^{13}$ En el caso español, la peligrosidad predelictiva encuentra su eco en la ley de vagos y maleantes de 1933. Esta ley, forjada al calor de las reivindicaciones de los médicos alienistas, hace posible que la política criminal trascienda el campo de la acción penal y actúe en el terreno de la higiene social y la profilaxis delictiva. Véase Campos (2013: 10-11).

${ }^{14}$ Sobre las instituciones dedicadas al estudio biológico de la criminalidad en Bélgica, Alemania, Estados Unidos, véase Renneville (2016, pp. 386-395). Para el caso español, véase Campos (2013, p. 7 y ss.) y para el francés, Michel David (1993). otorga a ciertos grupos profesionales (psiquiatras, médicos, trabajadores sociales, criminólogos...) la tarea de evaluar y pronosticar la criminalidad contenida en la subjetividad de los penados. Es ahí, en este contexto, cuando se demanda a esos grupos profesionales la tarea de definir, no la responsabilidad jurídica de un sujeto criminal, sino el régimen de anomalías mentales susceptibles de ponerse en relación con la infracción (Foucault, 2001: 35$)^{15}$. El propio Foucault identifica esta conexión del saber médico y el poder judicial como un aspecto básico del complejo penal moderno. Sin ella es difícil comprender el dictum foucaultiano de que la ley funciona como una norma. Todo su argumento consiste en mostrar que la aplicación de la ley penal, en tanto que implica este espacio, no puede realizarse sino por medio de normas extrajurídicas, que obedecen a otra racionalidad y que convierten al juez en un mero interlocutor de diversos cuestionarios y procesos de investigación (Garland, 2018, p. 329). Esta interpenetración de lo jurídico y lo no-jurídico, de las formas legales y las formas de prueba elaboradas en el ámbito de las ciencias humanas, comporta el desarrollo de un espacio penal cada vez más autónomo, basado en el conocimiento especializado y en prácticas de individualización penal.

3. El tercer blanco de ataque contra la doctrina clásica es la crítica de la uniformidad de las penas. Para la jurisprudencia anterior la uniformidad de las penas era uno de los corolarios básicos de las teorías del contrato social, perfectamente compatible con el legalismo del proceso, el castigo proporcional y la igualdad jurídica. El argumento era claro: dado que los individuos nacen libres e iguales, el Derecho penal debe juzgar según estas premisas. Todos los que hayan cometido la misma especie de delito serán sometidos a idénticas penas, con independencia de cuales fueren las desigualdades materiales o simbólicas de los acusados. El juez no era más que un instrumento mecánico de aplicación de la pena: un engranaje que distribuía la pena de acuerdo con la ley (Saleilles, 1923, p. 53). Por eso el castigo

\footnotetext{
${ }^{15}$ En Francia, la circular Chaumié (1905) camina en esa dirección. Insta a los médicos a que sus peritajes no se limiten a certificar un estado de demencia por parte del acusado, sino que precisen «las anomalías mentales o psíquicas que pueden atenuar su responsabilidad». Esta formulación traducía la "monomanía homicida" teorizada por Esquirol, pero también las diversas formas de locura moral (imbecilidad moral, debilidad mental, cleptomanía, etc.) planteadas por los alienistas y no asociadas al delirio sino a la neurosis, a lo que tiene que ver con las afecciones nerviosas o la inestabilidad psicológica.
} 
debía proceder de manera uniforme, porque al tratarse de un sistema basado en la igualdad de trato, la uniformidad representaba la fórmula más coherente de castigo: una pena aplicable a todos por igual, con independencia de la personalidad delictiva y la biografía del infractor.

A pesar de la modernidad de la fórmula, este postulado empezó a cuestionarse en las postrimerías del siglo XIX. Lejos de percibirse como un avance en materia penal, la uniformidad se entendía, por parte del saber criminológico y los sectores más innovadores de la ciencia penal ${ }^{16}$, como una falta de refinamiento. Una medida, que, aun siendo bienintencionada, no acertaba a conseguir la enmienda del individuo, ya que imponía un tratamiento uniforme que ignoraba las desigualdades naturales de los individuos, ejerciendo así, paradójicamente, un tratamiento desigual, sin relación alguna con los caracteres fisio-psicológicos de los individuos (ibíd., p. 56). El resultado, denunciaban, fue un uso torticero e indiscriminado de la prisión, que tildaban de absurdo e ineficaz cuando adoptaba la forma del aislamiento celular ${ }^{17}$, o que incluso contribuía a la reincidencia criminal cuando se aplicaba (la mayoría de las veces) en forma de penas $\operatorname{cortas}^{18}$.

Si la pena debe medirse en proporción a la temibilitá del agente, las medidas deben asumir un carácter individualizado e indeterminado. La pena no debe ser la retribución de tal cantidad de falta con tal otra cantidad de castigo, sino una "defensa correspondiente al poder que el delincuente tiene de hacer daño y a sus probabilidades de readapta-

\footnotetext{
${ }^{16}$ Consciente de que la lucha contra la criminalidad presupone un conocimiento exacto de ella, Franz von Liszt (1994, p. 133) vio la necesidad de compaginar los avances de las nuevas disciplinas (antropología criminal, estadística criminal, sociología criminal) con la ciencia del Derecho penal. Para ello Liszt fundo junto a Adolphe Prins y Gérard Van Hamel la Unión Internacional de Derecho penal en 1889 , cuyo principal cometido era buscar la trascendencia de sus postulados en el ámbito legislativo: implementar distinciones entre los criminales habituales y los accidentales, promover las sentencias indeterminadas y el sistema progresivo, elaborar medidas de prevención del delito a través de la higiene social, etc.

${ }^{17}$ Para Ferri (2004b, p. 317), el aislamiento celular jamás puede contribuir a la enmienda de los condenados corregibles. En lugar de fortalecer, debilita el sentido moral y social del detenido, ya de por sí atrofiado.

${ }^{18}$ Según Prins (2018, pp. 58-64), la reincidencia estaba alimentada por los tribunales correccionales, quienes, instalados en la estrechez de miras de la jurisprudencia clásica, abusaban de las penas cortas amparándose en la escasa gravedad del delito cometido y en la sola consideración del acto pasajero del acusado. La misma relación entre la reincidencia y las penas cortas se encuentra en Liszt (1994, pp. 119-123)
}

ción social" (Ferri, 2004a, p. 267). Se trata de un giro copernicano en el ámbito del Derecho penal: en vez de adaptar la pena a la gravedad del crimen, aquella debe adaptarse a la naturaleza del criminal (Saleilles, 1923, p. 109). La elección de la pena viene condicionada así por el tipo de criminalidad latente que se deduce de cada tipología criminal. Más que una clasificación de los crímenes, lo que se busca es una clasificación "científica" de los criminales a fin de determinar las penas que mejor podrían ejecutar su enmienda moral (ibíd., p. 110). El objetivo no es la detención temporal por un período fijado de antemano (Garofalo,1885: 359), sino articular un sistema de penas ajustado a la naturaleza del peligro que la individualidad permanente (y no el acto pasajero) del culpable hace correr a la sociedad (Prins, 2018, p. 50). La justicia, lo que debe hacer, no es diversificar solamente las cuantías de una pena única, sino diversificar los regímenes y crear instituciones y establecimientos nuevos (ibíd., p. 51).

De ahí la relevancia de los pronósticos "científicos" referidos a la criminalidad del criminal. Sin ellos, sin esa red de informes médicos, psiquiátricos y policiales, apenas sería posible articular un sistema punitivo basado en la adaptación de las penas al potencial de corrección susceptible de pronosticarse para cada tipología criminal. En este sentido, cabe recordar algunas propuestas discutidas en congresos penitenciarios y aplicadas en la época finisecular, todas ellas auspiciadas desde las filas de la escuela positiva (Ferri, Garofalo), pero también por juristas tan influyentes como Raymond Saleilles y Adolphe Prins. Lo primero que llama la atención es que la prisión pierde la centralidad que había detentado en la segunda mitad del siglo XIX, cuyo uso se considera contraproducente (produce reincidencia) si se aplica a todas las categorías criminales por igual. Frente a ello, se aboga por un sistema de penas adaptado a las diversas categorías de criminales. Para los asesinos instintivos, que matan por placer o sin provocación de la víctima, Garofalo (1885, pp. 338-342) recomendaba la pena de muerte o la reclusión ilimitada en las casas de locos criminales. Tanto la naturaleza del crimen como la ferocidad de su ejecución indican al juez la insensibilidad moral y la crueldad instintiva de la que fueron portadores esos criminales: de ahí la imposibilidad de su enmienda y la pertinencia de su eliminación o segregación ilimitada. Si hablamos en cambio de homicidas no instintivos, personas que han cometido un homicidio en legítima defensa o por cuestiones relativas al honor o la venganza, el tratamiento represivo debía ser diferente. Para ellos (ibíd., pp. 346-350), lo más conveniente 
es el destierro o la deportación en libertad en una isla o una colonia por un periodo variable de años, pasados los cuales, y en vista de informes minuciosos, el juez resolverá la continuación o el fin de la pena. En estos casos, como el crimen estaba originado por un motivo exterior (la honra, la venganza, defensa), el juez no podía concluir la insociabilidad permanente del culpable, por lo que la posibilidad de enmienda era factible. Otra tipología delictiva lo constituían las personas culpables de malos tratos, secuestro, violación o heridas, para las cuales se reclamaba una indemnización económica o bien su reclusión forzada en una compañía de trabajo, si se trataba de personas insolventes (ibíd., pp. 349-352). Tratándose de delincuentes habituales, culpables de robos, estafas, falsificaciones y coacciones físicas, Garofalo (ibíd., p. 354) apuesta por la deportación perpetua en una colonia naciente, donde la población sea escasa y el trabajo constituya una condición indispensable para la propia supervivencia ${ }^{19}$.

Otra alternativa al uso de la prisión es la suspensión del juicio a prueba o probation. Aplicada en casos donde el carácter del infractor (no reincidente) o la índole de la infracción (delito leve) hacen desaconsejable el encierro, esta medida consiste en la suspensión del fallo o de la ejecución de la condena por un tiempo indeterminado. Como contrapartida, el sujeto debe cumplir una sanción consistente en la obligatoriedad de reportarse ante un funcionario especial, que supervisa su conducta y el cumplimiento de ciertos estándares en su régimen de vida. En caso de ser así, el juicio queda prescrito y no se dictará la condena. Pero si no se produce la readaptación o el sancionado deja de personarse ante el oficial, este último deberá informarle al juez y acabará ejecutándose la condena suspendida ${ }^{20}$. Reflexiones muy similares se aplican a la libertad condicional, variante europea de la probation. Sin ser tan estricta como la probation, la libertad condicional prescinde de la vigilancia ejecutada por el funcionario, siendo únicamente la reincidencia delictiva lo que hace perder el beneficio de la suspensión de la pena.

\footnotetext{
${ }^{19}$ En Francia, la Ley Waldeck-Rousseau de 1885 reintroduce la deportación a las colonias (Guayana, Nueva Caledonia, Argelia) de los individuos catalogados como incorregibles. Desde 1885 hasta 1900 , cerca de 10.000 reincidentes fueron evacuados, si bien esta cifra apenas eclipsa el número de condenados a prisión. Véase Perrot (2001, pp. 184-185).

${ }^{20}$ Tales medidas empezaron a implantarse en los Estados Unidos. Primero, en Boston, a partir de 1870 y luego en Massachussets, desde 1880. En Inglaterra, su implantación se remonta a la ley de 1907 de Suspensión del juicio a prueba. Véase Ferri (2004b, pp. 325-326) y Garland (2018, pp. 307-308).
}

Ambas medidas representan sentencias con una clara función preventiva, aplicándose en la mayoría de los países desde finales del siglo $\mathrm{XIX}^{21}$.

Esta clasificación apenas esbozada no es una representación real de las diversas legislaciones finiseculares. La propuesta de Garofalo, aunque discutida y promovida en múltiples congresos, jamás se aplicó en un país concreto, pero recoge algunas innovaciones que empezaron a incorporarse en las legislaciones penales, si bien la prisión continuó desempeñando un papel importante, aunque ya no exclusivo ${ }^{22}$. Además, aunque la prisión sea todavía la respuesta punitiva habitual, su uso empezó a modularse según una racionalidad basada en la indeterminación y en la creación de órganos técnicos encargados de fijar la duración de la sentencia en su fase ejecutivo-penal. Habitualmente se le denomina indeterminación de la pena y Foucault lo leyó como el advenimiento o la emergencia de lo penitenciario entendido como un dispositivo estratégico complejo.

Entramos aquí en un aspecto esencial ya que, si lo relevante es adaptar la pena al tipo delictivo, la sentencia del juez debe adoptar un carácter provisional, susceptible de determinarse a tenor de la evolución o la regresión del interno en su fase ejecutivo-penal. Así, una vez se declara el fallo por parte del juez, es la administración penitenciaria la única que fija la duración de la pena, al punto de hacerla cesar cuando juzga que la pena se ha vuelto inútil (Saleilles, 1923, p. 279). Dicho de otro modo, desde finales del siglo XIX las legislaciones penales se han configurado sobre la base de las sentencias indeterminadas y el sistema progresivo ${ }^{23}$. Según

\footnotetext{
${ }^{21}$ El sistema de libertad condicional se instaura en Europa a partir de las leyes belgas y francesas de 1888 y 1891, respectivamente. Poco después, a instancia de la Unión Internacional de Derecho penal, se recomienda a los legisladores de todos los países la adopción del principio de la libertad condicional. Acto seguido, se implantó en la mayoría de los países europeos (Portugal, España, Grecia, Italia, Dinamarca, Alemania, etc.). Sin ser masiva, su implantación en Francia representa para el año 1893 un 12\% de las condenas (véase Ferri, 2004b, p. 328).

${ }_{22}$ Dominante, porque a pesar de verse reducida a causa de la aparición de las sentencias condicionales (probation, libertad condicional, colonias agrícolas, talleres industriales) y las penas pecuniarias, la prisión seguía ocupando una parte importante en el conjunto de la distribución porcentual de las sentencias. Véanse por ejemplo los datos suministrados por Rusche y Kirchheimer (2004, pp. 176-182) para los países europeos en el periodo 1880-1930.

${ }^{23}$ El origen de la «sentencia indeterminada» hay que buscarlo en el reformatorio de Elmira, en 1876. Más información sobre el origen de las sentencias indeterminadas en Saleilles (1923, p. 271 y ss.) y Rivera (2011, pp. 94-99).
} 
este planteamiento, el criminal solo recobra su libertad cuando manifiesta signos que dan cuenta de la regeneración que se ha producido en su interior. Ocurre sin embargo que la apreciación de tales signos solo puede realizarse en el trascurso de la ejecución de la pena. Son los propios internos quienes, mediante la evolución de su conducta, determinan la duración de la condena en su fase ejecutivo-penal. El juez solo juzga un rango de pena a cumplir, no una cantidad fija de condena. Por eso, la pena se convierte en un mecanismo constante de evaluación, es como si la ejecución penal debiera guiarse por un trabajo permanente de registro y anotación, un trabajo que lejos de separarse de la obra del juez la continúa mediante una labor confiada a órganos y comisiones especiales (Ferri, 2004b, p. 273). De ese modo, la prisión se carga de saberes y grupos profesionales. El carácter provisional de las sentencias hace que la prisión se convierta en algo más que un lugar de ejecución de la pena. Es a la vez un recinto cerrado en el que la puesta en marcha de relaciones de poder disciplinarias, basadas en la captura exhaustiva del cuerpo (de sus gestos, tiempos, actividades), hace posible la creación de un sistema de documentación individualizante y permanente de los individuos (Foucault, 1976, p. 252). Mucho más que en la escuela, el hospital o el cuartel, el examen carcelario se ocupa de todos los aspectos del individuo: la aptitud para el trabajo, la actividad moral, la conducta cotidiana, su potencial de adaptabilidad... Lo cual queda reflejado en los múltiples informes (psicológicos, educativos, criminológicos, educativos, etc.) que evalúan la marcha de la conducta del reo dentro de la prisión.

Asimismo, la valoración y el pronóstico de los informes trae aparejada la posibilidad de acogerse a beneficios penitenciarios. Si algo caracteriza al sistema de sentencias indeterminadas es su defensa a ultranza de que la ejecución de las penas debe modularse en función de la individualidad de los detenidos. Y no solo porque los internos sean clasificados de distintas maneras, según la tipología criminal y las técnicas correctivas utilizadas, sino porque la clasificación interna debe supeditarse a la fase de readaptación en la que se encuentre el reo $^{24}$. Tanto es así que el reo puede acceder a me-

\footnotetext{
${ }^{24}$ En España, el Real Decreto de 1913 ya contemplaba el sistema progresivo (artículos 236 y 241) de los centros penitenciarios. No obstante, hay que esperar a la Ley Orgánica General Penitenciaria de 1979 (LOGP) para ver una verdadera individualización científica del tratamiento y de la clasificación. En concreto, su título III indica (artículos $62,63,72)$ que el tratamiento penal debe individualizarse teniendo en cuenta el «diagnóstico de personalidad criminal» y «los métodos-biológicos, psiquiátricos, psicológi-
}

canismos de liberación anticipada, toda vez que la comisión de expertos determine una prognosis criminal favorable, esto es, que su puesta en libertad sea compatible con la seguridad pública ${ }^{25}$.

El cambio es total con respecto a la doctrina clásica. En lugar de calcular la pena en función del acto realizado, se instaura un sistema que, paulatinamente, mediante la incorporación de saberes y grupos extrajurídicos, establece sentencias sobre la base de diagnósticos relativos a la peligrosidad y la adaptabilidad del individuo, términos que remiten no tanto al nivel de las infracciones efectivas sino al de las virtualidades de comportamiento que ellas representan (Foucault, 1973a, p. 97). Las penas son provisionales (o indeterminadas) porque al igual que sucede con las terapias médicas, el juez no puede prever por anticipado el tiempo necesario para rehacer un temperamento (Saleilles, 1923, p. 268). Por eso es indeterminado, porque la constatación de que el detenido ha recobrado su sentido moral es algo que solo puede realizarse en el trascurso de la ejecución de la pena, por parte de expertos que siguen de cerca la evolución del condenado y juzgan la probabilidad de su comportamiento futuro en libertad.

Así, cuanto más iniciativa concede el juez a la administración penitenciaria, más funciona la ley como una norma: más poder tiene la segunda para adaptar el régimen y la duración de la condena a la tipología delictiva y el potencial de readaptación del criminal. Estamos así ante lo que Foucault (1976, p. 228) llamó lo penitenciario, un orden que, sin ser del todo ajeno a lo judicial, aporta técnicas y procedimientos correctivos que se construyen sobre la base de un campo permanente y continuo de visibilidad. Sin embargo, la clasificación de los individuos en este campo no busca la mera obediencia a las normas impuestas, se trata por el contrario de que las inadecuaciones a las técnicas de corrección sean localizadas, conocidas y clasificadas, a fin de registrar las aptitudes y virtualidades de cada individuo, pero también las inadecuaciones que se deben encauzar, corregir o excluir. Lo que caracteriza al orden penitenciario es lo que Foucault llama el poder de la norma, que no es solo un poder que homogeniza las diferencias, sino un poder que obli-

cos, pedagógicos y sociales, con relación a la personalidad del interno»».

${ }^{25}$ El artículo 67 de la LOGP habla de un informe pronóstico final que juzgue, además de los resultados conseguidos por el tratamiento, «la probabilidad sobre el comportamiento futuro del sujeto en libertad». Todo ello, concluye, "se tendrá en cuenta en el expediente para la concesión de la libertad condicional». 
ga a la homogeneidad para poder individualizar (Legrand, 2003, p. 62). El matiz es fundamental: "lo penitenciario no es un espacio en el que solo se aplican decisiones judiciales, es un espacio en el que la acción punitiva del poder judicial queda reubicada en un conjunto más amplio de técnicas de corrección y transformación de los individuos". Técnicas que más que inducir un régimen uniforme de castigo, propician esquemas de clasificación individualizantes, así como una forma de castigo que no es únicamente un modelo reducido de tribunal, sino una técnica basada en la localización y la corrección de las fracciones más ínfimas de las conductas. Técnicas que más que inducir un régimen uniforme de castigo, propician esquemas de clasificación individualizantes, así como una forma de castigo que no es únicamente un modelo reducido de tribunal, sino una técnica basada en la localización y la corrección de las fracciones más ínfimas de las conductas (Foucault, 1998, p. 183) ${ }^{26}$.

Lo penitenciario se convierte así en un espacio de creación y acumulación documental, un orden en el que la intensificación y la ramificación de las técnicas disciplinarias permite fijar a los individuos en un mecanismo constante de objetivación a través del cual se los diferencia y se los sanciona. Paralelamente, la anotación minuciosa de las conductas irregulares permite comparar la evolución del individuo con el diagnóstico de capacidad criminal que inspiró originalmente su tratamiento. Estamos así ante una forma de castigo que guarda una relación estrecha con la escritura, una escritura que resulta de la presión minúscula y continua que rodea el cuerpo de los individuos y que no obstante permite hacer de la pena un mecanismo constante de enjuiciamiento (Foucault, 2005, p. 63).

\section{CONCLUSIONES}

Como hemos visto, los principios fundamentales de la escuela clásica utilitarista nos permiten caracterizar a dicha tendencia como una criminología administrativa y legal. Su gran ventaja fue que estableció un marco procesal fácil de aplicar; redujo la función

\footnotetext{
${ }^{26}$ Por ello Foucault acuña un término que antes no había utilizado, el dispositivo, y que tiene importancia en su evolución conceptual por cuanto el dispositivo se establece por antonomasia como la herramienta privilegiada de la microfísica del poder, y por tanto sobre el continuum de las relaciones de poder. Entre sus corolarios se encuentra la forma en que subraya aquellos mecanismos e instancias que promueven el tratamiento -o un tratamiento determinado- de la multiplicidad. Así va a ser el dispositivo carcelario: esas posibilidades de visibilidad y enunciabilidad, esas maquinarias punitivas que revelan el funcionamiento de las prácticas más allá de lo que se ve o se habla.
}

del juez a la aplicación de la ley, mientras que a esta le correspondía fijar exactamente una pena para cada delito y para cada grado de un mismo delito. Deliberadamente, y en pro de la uniformidad administrativa, se hizo caso omiso de cuestiones enigmáticas acerca de los motivos y las causas últimas del comportamiento. Tal era la concepción clásica de la justicia: una escala exacta de penas para actos iguales, sin referencia a la naturaleza del individuo en cuestión y sin considerar las circunstancias especiales de la comisión del acto. La medida del castigo se establecía con la vista puesta en la prevención disuasoria, de manera que cuanto más atentase al bien público un delito, más intensa en tiempo debía ser la pena. El objetivo consistía en elegir aquellas penas que, guardada la proporción, fuesen capaces de producir la impresión más eficaz y duradera sobre los ánimos de los individuos. En gran medida, se trata únicamente de atender a los problemas de la administración del control social, y donde las teorías sobre la motivación humana, el libre albedrío, etc., son implícitas antes que explícitas.

Los límites de esa racionalidad punitiva clásica, así como las críticas vertidas ya desde finales del siglo XIX suponen la irrupción paulatina de otra episteme punitiva surgida como consecuencia de la colonización del espacio jurídico por parte de las teorías alienistas y los programas de acción criminológicos. No se trata de un programa planificado y preestablecido, sino de la confluencia de una serie de teorías y de programas de prevención penales que Foucault resumió como la constatación de que la ley funciona (cada vez) más como una norma (Foucault, 1976, p. 174), es decir, la transformación de la práctica judicial por la invasión de tecnologías provenientes del positivismo científico en diversas áreas ajenas a lo jurídico y que no actúan al mismo nivel que la ley soberana. La norma y sus principios significan para Foucault un proceso general de normalización social, política y técnica que comienza a desarrollarse ya en el siglo XVIII, y cuyos efectos se observan en distintas instituciones (cárcel, hospital, fábrica). No se define como una ley natural, sino gracias a la presión que puede ejercer en el ámbito donde se la aplica, por ello la norma posee un carácter inmanente, carece de necesidad y no puede depender de ella misma; no es exterior a sus formas fenoménicas en que aparece, que es el lugar donde se expresa como capacidad de regulación y ajuste, pero cada una de ellas tampoco constituye la encarnación perfecta del valor normativo. Es solamente una preferencia que ha obtenido, en un territorio en disputa, el privilegio de asu- 
mir su papel en tanto que ajuste dominante. En otras palabras, cabe considerar la norma como un concepto propiamente político, lo cual se halla en consonancia con la concepción que Foucault tiene sobre la política como conflicto, entre lo normal y lo patológico, entre lo normal y lo anormal. La norma funciona de acuerdo con un sistema binario de gratificación y sanción; para ella, castigar es corregir. Mientras la ley separa y divide, la norma pretende homogeneizar según criterios biopolíticos que aquí no podemos desarrollar. Sin embargo, no se debe plantear este fenómeno como una sustitución de la ley por la norma (médica, psiquiátrica...) sino más bien como una complementariedad, a veces problemática, pero no obstante en permanente búsqueda de su propia eficacia. En efecto, existe ahora un ámbito donde el juez, el abogado y el jurado evalúan el comportamiento en función de opciones morales, mientras que se convoca a diversos expertos en conducta desviada según lo estime oportuno el tribunal, para exponer sus explicaciones deterministas del comportamiento, como base de una atenuación de la pena (por ejemplo, la ejecución condicional de la condena) o de la "reforma" (por ejemplo, modificar el ambiente que condiciona al delincuente confinándolo en una institución especializada).

Esta nueva criminología de carácter etiológico, en su función auxiliar y legitimadora con relación al sistema penal y al sistema jurídico, parte de la suposición de que existe una cualidad natural de comportamientos y de sujetos que tienen una característica que los distingue del resto de sujetos: esa cualidad natural sería la criminalidad. Siendo la criminalidad una entidad ontológica, sería posible investigar sus causas y poner la ciencia de las causas al servicio de la práctica que debe combatirla. No se puede, pues, plantear una investigación de las causas de la misma forma que la indagación articulada respecto a objetos definidos por normas, convenciones o evaluaciones sociales e institucionales. Aplicar a objetos de ese tipo un conocimiento causal-naturalista, produce una "reificación" de los resultados de esas definiciones normativas. La "criminalidad", "los criminales" son, sin duda, objetos de este tipo: resultan impensables sin la intervención de procesos institucionales y sociales de definición, sin la aplicación de la ley penal por parte de las instancias oficiales y por último sin las definiciones y las reacciones no institucionales. $\mathrm{He}$ ahí la complementariedad, aunque problemática, que no el antagonismo, entre los campos propios de las ciencias positivas y el ámbito jurídico. Y es asimismo este carácter plural el que permite la emergencia de lo penitenciario entendido como un dispositivo estratégico complejo, que no solo combina lo múltiple de las prácticas y las ideologías, sino que además consigue cambiar el punto de vista de la función por el de la estrategia.

En efecto, la articulación de prácticas y saberes múltiples, el carácter estratégico que no meramente funcional de tales dispositivos penales ha constituido un nuevo objeto de saber y de práctica: el criminal. Si en el modelo clásico-utilitarista el acto criminal, como todo comportamiento humano, es el resultado de una elección individual y de la voluntad de los sujetos, y por tanto los criminales se diferencian de los no criminales solo por el hecho de que con sus acciones han infringido la ley; ahora la configuración de esta nueva episteme etiológica es profundamente distinta. De hecho, a pesar de mantener la centralidad del sistema legal con sus funciones de disuasión y retribución, cambia la representación de los sujetos criminales: se les presenta como individuos que deben ser analizados en su especificidad, curados y posiblemente rehabilitados a través de líneas cada vez más precisas de normalización. La rehabilitación de los individuos pasa gradualmente de un objetivo accesorio del sistema penal a una finalidad central y predominante de la nueva configuración.

Todo este paso de la ley a la norma tal como insiste Foucault muestra la génesis y evolución de un dispositivo puesto al servicio de la defensa y exigencias del sistema de producción capitalista industrial a través de una economía política del cuerpo, una tecnología de control disciplinario que actúa sobre el cuerpo productivo para gobernarlo y regir su vínculo con otros cuerpos para organizarlos "científicamente" como paso a su transformación en capital. La otra parte está representada por el papel de este dispositivo de control en la reproducción de la fuerza de trabajo asalariada y esta dimensión nos explica el éxito histórico de la institución carcelaria. Aquí subyace la motivación profunda de ambas epistemes punitivas. La ideología contractual-igualitaria del clasicismo utilitarista había escondido la realidad de la explotación fabril o lo que es lo mismo, el salario como justa retribución del trabajo y la pena como medida justa de sus crímenes. Por lo mismo, la ideología positivista-correccionalista ocultó la realidad de la disciplina y la dominación, haciendo de los sistemas punitivos el laboratorio por excelencia de mecanismos de regulación social más amplios una vez las disciplinas y saberes anudados a ellas superasen los muros de las cárceles y se estableciese el gobierno a través de los expertos, la gestión del bienestar de la población y el correccionalismo penal. 


\section{BIBLIOGRAFÍA}

Álvarez-Uría (1983): Miserables y locos. Medicina mental y Orden social en la España del siglo XIX, Barcelona, Tusquets.

Baratta, A. (1986): Criminología crítica y crítica del Derecho penal. Buenos Aires, Siglo XXI.

Beccaria (2002 [1764]): De los delitos y las penas. Barcelona, Folio.

Bentham, J. (1826 [1811]): Teoría de las penas y de las recompensas. París, Casa de Masson e hijo.

Boullant, F. (2003): Michel Foucault et les prisons. París, PUF.

Campos, R. (2007): "Crimen y locura. La patologización del crimen en la España de la Restauración”, Norba. Revista de historia, $\mathrm{n}^{\circ}$ 20, pp. 85-105.

Campos, R. (2013): "La construcción del sujeto peligroso en España (1880-1936). El papel de la psiquiatría y la criminología, Asclepio. Revista de Historia de la Medicina y de la Ciencia, Vol. 65, $\mathrm{n}^{\circ}$ 2, CSIC.

Carrara, F. (1859): Programma del corso di diritto criminale, vol. I, Lucca.

Carrara, F. (1887): Programma del corso di diritto criminale, vol. II, Lucca.

David, M. (1993): Psychiatrie en milieu pénitentiaire. París, PUF.

Ferri, E. (2004a [1895a]): Sociología criminal. Tomo 1. Madrid, Centro Editorial de Góngora.

Ferri, E. (2004b [1895b]): Sociología criminal. Tomo 2. Madrid, Centro Editorial de Góngora.

Figueroa Navarro, $\mathrm{M}^{\mathrm{a}}$ C. (2000): Los orígenes del penitenciarismo español, Madrid, Edisofer.

Foucault, M. (1973a): La verdad y las formas jurídicas. Barcelona, Gedisa.

Foucault, M. (1973b): Moi, Pierre Rivière, ayant égorgé ma mère, ma scur et mon frère... Un cas de parricide au XIX $\mathrm{X}^{\mathrm{e}}$ siècle. París, Gallimard.

Foucault, M. (1976 [1975]): Vigilar y castigar. Nacimiento de la prisión moderna. Madrid, Siglo XXI.

Foucault, M. (1996 [1981]): "La evolución de la noción de individuo peligroso", La vida de los hombres infames. Buenos Aires, Altamira.

Foucault, M. (1998 [1976]): Historia de la sexualidad I. La voluntad de saber. Madrid, Siglo XXI.

Foucault, M. (2001). Los anormales. Curso del Collège de France (1974-1975), Madrid, Akal.

Foucault, M. (2005). El poder psiquiátrico. Curso del Collège de France (1973-1974), Madrid, Akal.

Garland, D. (2005 [2001]): Cultura del control. Crimen y orden social en la sociedad contemporánea. Barcelona, Gedisa.
Garland, D. (2018): Castigar y asistir. Una historia de las estrategias penales y sociales del siglo $\mathrm{XX}$. Buenos Aires, Siglo XXI.

Garofalo, R. (1885): Criminología. Estudio sobre el delito y sobre la teoría de la represión, Madrid, $\mathrm{s} / \mathrm{n}$.

Georget,E.(1825) : Examen médical des procès criminels des nommés Léger, Feldtmann, Lecouffe et al. París, Migneret.

Guignard, L. (2007): "Un réquisit de rationalité : responsabilité pénale et aliénation mentale au XIX ${ }^{\mathrm{e}}$ siècle" en Marco Cicchini y Michel Porret, (dir.), Les sphères du pénal avec Michel Foucault. Lausana, Antipodes, pp. 155-167.

Hierro, L. L. (1989): "Libertad y responsabilidad penal", Anuario de la Facultad de Derecho, $\mathrm{N}^{\circ} 1$, pp. 161-173.

Huertas, R. (2006): "Locos, criminales y psiquiatras: la construcción de un modelo (médico) de la delincuencia", Atopos, Vol. 8, pp. 14-21.

Ignatieff,(1978): A just measure of pain. The penitentiary in the industrial Revolution 1750-1850. Londres, McMillan Press.

Legrand, S. (2003): Les normes chez Foucault. París, PuF.

Liszt, F. von (1994 [1882]): La idea de fin en el Derecho penal. México, UnAm.

Pasquino, P. (1991): "Criminology: the birth of a Special Knowledge", en The Foucault effect. Studies in Governmentality. Chicago, University of Chicago Press, pp. 235-250.

Pavarini, M. y Melossi, D. (1980 [1977]): Cárcel y fábrica. Los orígenes del sistema penitenciario (siglos XVI-XIX). México, Siglo XXI.

Perrot, M. (2001): Les ombres de l'histoire. Crime et châtiment au XIX siècle. París, Flammarion.

Prins, A. (2018 [1910]): La defensa social y las transformaciones del Derecho penal. Santiago de Chile, Olejnik.

Renneville, M. (2016): "La psychiatrie légale dans le projet de réforme du code pénal français (1930-1938)", Sixième Congrès de l'Association Européenne pour l'Histoire de la Psychiatrie, Sep. 2005, París.

Rivera, I. (2011): Política criminal y sistema penal. Viejas y nuevas racionalidades punitivas. Barcelona, Anthropos.

Rusche, G. y Kirchheimer, O. (2004 [1939]): Pena y estructura social. Bogotá, Temis.

Saleilles, R. (1923 [1898]): L'individualisation de le peine. Étude de criminaliste sociale. París, Félix Alcan.

Servan, J.-M. (1768): Discours sur l'administration de la justice criminelle, Ginebra. 